\title{
Human pharmacology of 5-epi-sisomicin (Sch 22591) following intramuscular administration
}

\author{
J. Blaser, R. Münch and R. Lüthy \\ Department of Medicine, University Hospital, Zürich, Switzerland
}

\begin{abstract}
5-epi-sisomicin was given as a single intramuscular injection of $1 \mathrm{mg} / \mathrm{kg}$ to six healthy male adults. Serum peak concentrations averaged $3.07 \mathrm{mg} / \mathrm{l}$, the mean elimination half life was $179 \mathrm{~min}$ and the mean $24 \mathrm{~h}$ urinary recovery was $85.3 \%$. Local and systemic tolerance was good.
\end{abstract}

\section{Introduction}

5-epi-sisomicin (Sch 22591) is a semisynthetic aminoglycoside which is derived from sisomicin (Testa et al., 1974). Introduction of a hydroxy group in position 5 of the deoxystreptamine ring results in an enhanced antibacterial activity against a great variety of Gram-positive and Gram-negative bacteria (Fu \& Neu, 1978; Kabins \& Nathan, 1978; Sanders, Sanders \& Goering, 1978; Watanakunakorn, 1978). 5-epi-sisomicin is either not, or less effectively, modified by most aminoglycoside modifying enzymes (Waitz et al., 1978; Vastola, Altschaefl \& Harford, 1980). In addition, 5-epi-sisomicin appears to be superior to other aminoglycosides in protecting mice infected with Pseudomonas aeruginosa (Goering, Sanders \& Sanders, 1978; Waitz et al., 1978). The purpose of this study was to investigate the pharmacokinetics of 5 -epi-sisomicin in humans after intramuscular injection of $1 \mathrm{mg} / \mathrm{kg}$ body weight and to evaluate local and systemic tolerance.

The results of this study have been presented previously as an extended abstract (Lüthy, Münch \& Blaser, 1980). Recently data from a similar study have been reported in this Journal (Amirak et al., 1985). However, some results presented in the paper by Amirak et al. (1985) differ substantially from the pharmacokinetic data obtained in our study. Hence, these data are presented here in detail and methodological differences between the two studies are addressed in the discussion.

\section{Methods}

Six healthy male volunteers, 21-28 years old, with a mean body weight of $69 \mathrm{~kg}$ $( \pm 11.5 \mathrm{~kg}$, S.D.) were enrolled in this study. The study was performed according to institutional policies, with written informed consent obtained from each participant. A dose of $1 \mathrm{mg} / \mathrm{kg}$ of 5 -epi-sisomicin was injected into the upper outer quadrant of the gluteal area. Thirteen venous samples were withdrawn from an arm vein, before the administration and 15,30, 45, 60 and 90 min and 2, 3, 4, 6, 8, 12 and $24 \mathrm{~h}$ following the im dose. After clotting at room temperature blood samples were centrifuged at 
$4^{\circ} \mathrm{C}$. Urine was sampled quantitatively during a $24 \mathrm{~h}$ period before administration of the drug and in seven fractions over a $72 \mathrm{~h}$ period following the injection. Serum and urine standards in the range of the expected concentrations were prepared on the study day with pooled antibiotic free human serum and $0.05 \mathrm{M}$ phosphate buffer, $\mathrm{pH} 7$, respectively. All standards and samples were frozen in liquid nitrogen and assayed within one week with a large plate agar diffusion method (Bennet et al., 1966). Concentrations of 5 -epi-sisomicin in the range of $0.5-8 \mathrm{mg} / 1$ were assayed in quintuplicate with Bacillus subtilis (spore suspension, Difco Laboratories, Detroit Michigan, U.S.A.) as the assay organism. Concentrations in the range of $0.016-0.5 \mathrm{mg} / 1$ were determined in quintuplicate with Staphylococcus epidermidis (ATCC 27626) as the assay organism. The precision of the assay was determined with ten spiked serum specimens in the range of $0.016-8 \mathrm{mg} / 1$. Each of these specimens was measured five times, revealing a coefficient of variation of $5.8 \%$.

Before and after study the following laboratory examinations were performed: haematocrit, haemoglobin, a complete blood count, erythrocyte sedimentation rate, fasting blood sugar, blood urea, nitrogen, serum creatinine, bilirubin, alkaline phosphate, transaminases, and total protein with albumin/globulin ratio. Complete urine analyses including microscopic examination were conducted. A $24 \mathrm{~h}$ creatinine clearance was determined before, during and after the study day.

Serum kinetics during the first $12 \mathrm{~h}$ after administration of the drug were analysed by an open two compartment model (Gibaldi \& Perrier, 1975). The pharmacokinetic parameters of the model (volume of distribution of the central compartment $V_{1}$, rate constants for transfer. between the two compartments $k_{12}$ and $k_{21}$ and rate constants

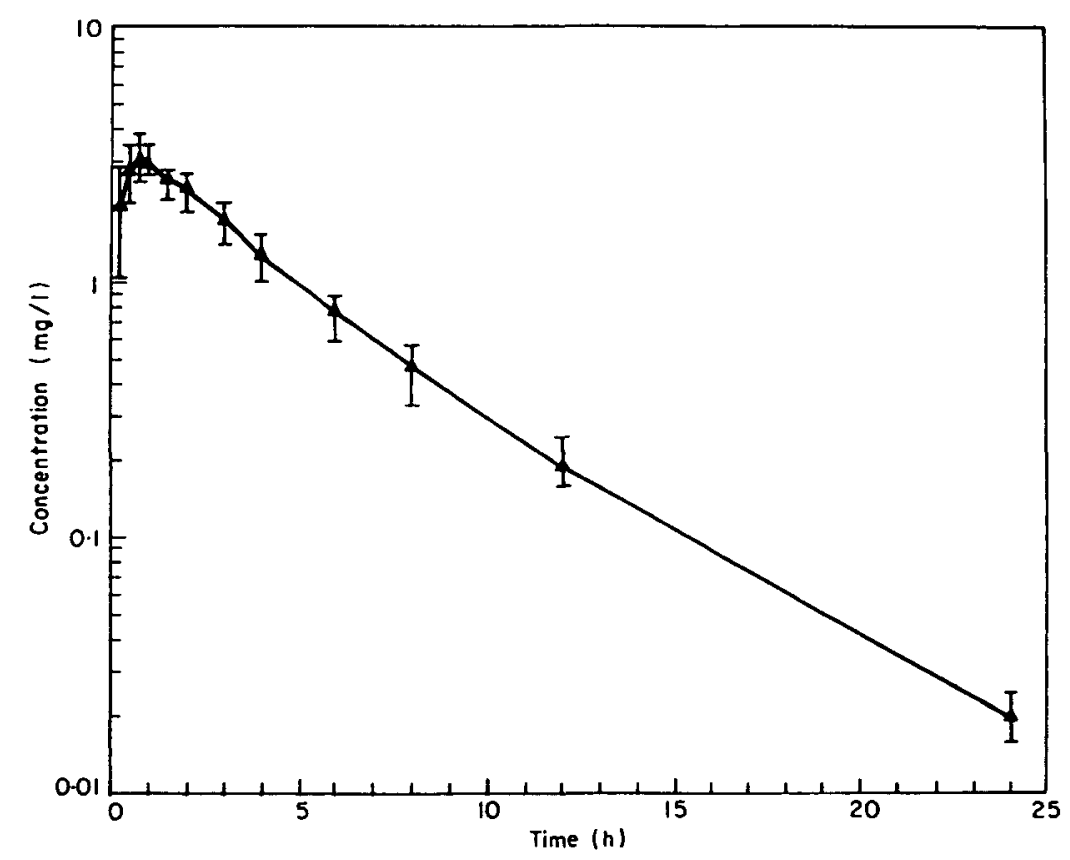

Figure 1. Mean and range of serum concentrations of 5-epi-sisomicin in six human subjects, following im administration of $1 \mathrm{mg} / \mathrm{kg}$. 
of absorption $\mathrm{k}_{\mathrm{a}}$ and elimination $k_{\mathrm{e}}$ ) were determined with a nonlinear fitting programme (Metzler, Elfring \& McEwen, 1974). The total volume of distribution $\left(V_{\mathrm{dss}}\right)$, body clearance $\left(\mathrm{Cl}_{b}\right)$ and elimination half life $\left(T_{1 / 2}\right)$ were defined as follows:

$$
V_{\mathrm{dss}}=V_{1} *\left(1+k_{12} / k_{21}\right) ; C l_{\mathrm{b}}=k_{e} * V_{1} ; T_{1 / 2}=\ln 2 / k_{\mathrm{e}} \text {. }
$$

\section{Results}

Serum kinetics of 5 -epi-sisomicin are shown in Figure 1. Peak serum levels ( \pm S.D.) averaged $3.07 \pm 0.44 \mathrm{mg} / \mathrm{l}$. The maximal concentrations were measured between 45 and $90 \mathrm{~min}$ after administration. The individual serum concentrations are given in Table 1. In five out of the six subjects $24 \mathrm{~h}$ serum concentrations were still above the sensitivity limit of the assay $(0.016 \mathrm{mg} / \mathrm{l})$, with an average concentration of $0.02 \mathrm{mg} / \mathrm{l}$. Analysis of the serum data from the first $12 \mathrm{~h}$ revealed a mean serum half life of $179 \pm 20 \mathrm{~min}$, a total volume of distribution of $15.9 \pm 1.91(0.23 \pm 0.031 / \mathrm{kg})$ and a body clearance of $78.4 \mathrm{ml} / \mathrm{min}$ per $1.73 \mathrm{~m}^{2}$ body surface area $(84.3 \pm 16 \mathrm{ml} / \mathrm{min})$, respectively. The half life of absorption from the muscular depot was determined as $46 \pm 13 \mathrm{~min}$.

Urinary recovery averaged $83.1 \%$ (range $79 \cdot 6-89 \cdot 3 \%$ ) for the first $12 \mathrm{~h}$ and $92.2 \%$ $(88.7-99.5 \%)$ for the first $72 \mathrm{~h}$ (Figure 2). The urinary excretion rate decreased exponentially from $15.5 \%$ of the dose per hour in the first $4 \mathrm{~h}$ interval to less than $0.2 \% / \mathrm{h}$ after $12 \mathrm{~h}$. From 36 to $72 \mathrm{~h}$ the hourly excretion rate remained constant at a level of $0.1 \%$ of the administered dose. These data suggest a continuing excretion beyond the last collection period.

One patient had diarrhoea one day after drug administration, two reported dull pressure in the head for less than $12 \mathrm{~h}$ and one subject reported a faint pressure in both ears lasting $15 \mathrm{~min}$. No significant changes in the haematology, serum chemistry or urine analysis were recorded. No local side effects attributable to 5-epi-sisomicin were recorded.

\section{Discussion}

The serum kinetics of 5-epi-sisomicin were studied in six healthy volunteers. Compared to other aminoglycoside antibiotics the peak concentrations of $3.07 \mathrm{mg} / \mathrm{l}$ following im doses of $1 \mathrm{mg} / \mathrm{kg}$ were rather low (Gruenwaldt et al., 1976; Riff \& Moreschi, 1977). However, Meyers et al. (1976) also observed peak levels of $3.08 \mathrm{mg} / \mathrm{l}$ for sisomicin. Amirak et al. (1985) reported for 5-epi-sisomicin a mean peak concentration of $4.82 \mathrm{mg} / \mathrm{l}$ which is $57 \%$ higher than that found in the present study. This discrepancy might be explained in part by the fact that in the study of Amirak et al. (1985) the standards were prepared in horse serum as opposed to pooled human serum in the present study. The mean volume of distribution of 5 -epi-sisomicin $(0.231 / \mathrm{kg})$ is comparable to data reported for other aminoglycosides (Schentag et al., 1977; Blaser et al., 1983a,b).

The serum concentrations declined within the first $12 \mathrm{~h}$ after the dose according to a mean serum half life of almost $3 \mathrm{~h}$. This is longer than half lives reported for other aminoglycosides in healthy young subjects (Gruenwaldt et al., 1976; Blaser et al., 1983a). The glomerular filtration rate of the six subjects was normal, with a mean creatinine clearance of $137 \mathrm{ml} / \mathrm{min}$ and serum creatinine values between 0.7 and $1 \cdot 1 \mathrm{mg} / 100 \mathrm{ml}$. Amirak et al. (1985) reported a mean serum half life for 5-epi-sisomicin of $2.3 \mathrm{~h}$. However, these data were derived only from serum concentrations measured 
Table I. Serum concentrations of 5-epi-sisomicin $(\mathrm{mg} / \mathrm{l})$ in six human volunteers following im administration of $1.0 \mathrm{mg} / \mathrm{kg}$

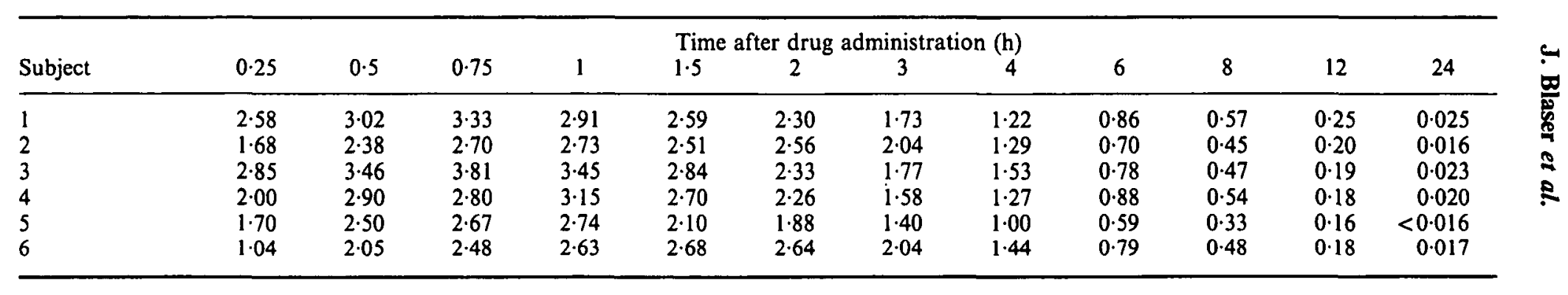




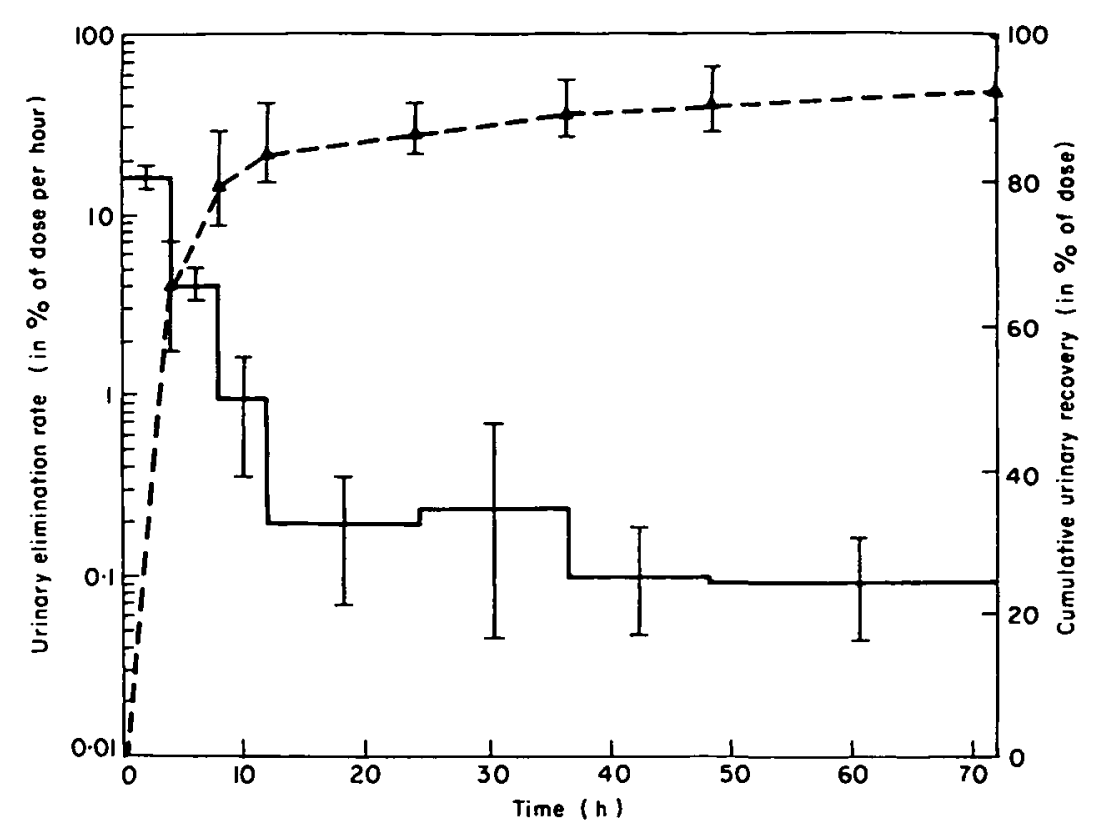

Figure 2. Mean and range of urinary elimination rate (full line, left hand scale) and cumulative urinary recovery rate (broken line, right hand scale) in six human subjects, following im administration of $1 \mathrm{mg} / \mathrm{kg}$.

within the first $4 \mathrm{~h}$ after dosing. After this time the serum levels fell below the detection limits $(>1 \mathrm{mg} / \mathrm{l})$ of the assay used in their study. The low sensitivity limit of the assay used in the present study $(0.016 \mathrm{mg} / \mathrm{l})$ allowed us to determine serum levels for up to $24 \mathrm{~h}$ after the administration of the dose.

However, the analysis of the serum data by means of a two compartment open model was limited to the $12 \mathrm{~h}$ period after drug administration. The $24 \mathrm{~h}$ serum concentrations had to be excluded because they were consistently higher than expected according to the half-life of elimination found during the first $12 \mathrm{~h}$ (Figure 1). For simulations over a longer time period a three compartment model would be needed. This finding is consistent with the concept of the presence of a deep compartment in which aminoglycoside antibiotics accumulate in the course of therapy (Schentag et al., 1977; Blaser et al., 1983a,b). The urinary excretion data strongly support this concept. After a distinct exponential decline of the urinary excretion rate during the initial $12 \mathrm{~h}$ period, the renal elimination remains fairly constant during the following $60 \mathrm{~h}$. These data suggest the existence of a deep compartment which releases the accumulated drug at the rate of approximately $0.1 \%$ of the administered dose per hour. The urinary recovery rate of $92.2 \pm 4.8 \%$ (mean \pm S.D.) after $72 \mathrm{~h}$ together with the finding of the prolonged elimination which appears to continue beyond $72 \mathrm{~h}$ suggest that no significant non-renal elimination occurs.

\section{References}

Amirak, I. D., Williams, R. J., Chung, M. \& Noone, P. (1985). The single-dose pharmacokinetics of 5-epi-sisomycin (Sch 22591) in human volunteers. Journal of Antimicrobial Chemotherapy 15, 607-11. 
Bennet, J. V., Brody, J. L., Benner, E. J. \& Kirby, W. M. M. (1966). A simplified accurate method for antibiotic assay of clinical specimens. Applied Microbiology 14, 170-7.

Blaser, J., Rieder, H., Niederer, P. \& Lüthy, R. (1983a). Biological variability of multiple dose pharmacokinetics of netilmicin in man. European Journal of Pharmacology 24, 399-406.

Blaser, J., Rüttimann, S., Bhend, H. J. \& Lüthy, R. (1983b). Increase of amikacin half-life during therapy in patients with renal insufficiency. Antimicrobial Agents and Chemotherapy 23, 888-91.

Fu, K. P. \& Neu, H. C. (1978). Activity of 5-episisomicin compared with that of other aminoglycosides. Antimicrobial Agents and Chemotherapy 14, 194-200.

Gibaldi, M. \& Perrier, D. (1975). Multicompartment model. Drugs and Pharmaceutical Sciences $1,45-56$

Goering, R. V., Sanders, C. C. \& Sanders, W. E. (1978). Comparison of 5-episisomicin (Sch 22591), gentamicin, sisomicin and tobramycin in the treatment of experimental Pseudomonas infection in mice. Antimicrobial Agents and Chemotherapy 14, 824-8.

Gruenwaldt, G., Doenicke, A., Scheer, M. \& Fink, H. (1976). Vergleichende Untersuchungen zur Pharmakokinetik von Sisomicin und Gentamicin. Infection 4, 370-5.

Kabins, S.A. \& Nathan, C. (1978). In vitro activity of 5-episisomicin in bacteria resistant to other aminoglycoside antibiotics. Antimicrobial Agents and Chemotherapy 14, 391-7.

Lüthy, R., Münch, R. \& Blaser, J. (1980). Human pharmacokinetics of 5-epi-sisomicin. In Proceedings of the 11th International Congress of Chemotherapy and the 19th Interscience Conference on Antimicrobial Chemotherapy (Nelson, J. D. \& Grassi, C. Eds), pp. 688-90. American Society for Microbiology, Washington D.C.

Metzler, C. M., Elfring, G. L. \& McEwen, A. J. (1974). A users manual for nonlin and associated programs. Research and Biostatistics, The Upjohn Co., Kalamazoo, Michigan.

Meyers, B. R., Hirschman, S. Z. Yancovitz, S. \& Ribner, B. (1976). Pharmacokinetic parameters of sisomicin. Antimicrobial Agents and Chemotherapy 10, 25-7.

Riff, L. J. \& Moreschi, G. (1977). Netilmicin and gentamicin comparative pharmacology in humans. Antimicrobial Agents and Chemotherapy 11, 609-14.

Sanders, C. C., Sanders, W. E. \& Goering, R. V. (1978). In vitro studies with Sch 21420 and Sch 22591 activity in comparison with six other aminoglycosides and synergy with penicilin against enterococci. Antimicrobial Agents and Chemotherapy 14, 178-84.

Schentag, J. J., Waitz, J. A., Miller, G. H., Moss, E. \& Chin, P. J. S. (1978). Chemotherapeutic evaluation of 5-episisomicin (Sch 22591), a new synthetic aminoglycoside. Antimicrobial Agents and Chemotherapy 13, 41-8.

Testa, R. H., Wagman, G. H., Daniels, P. J. L. \& Weinstein, M. J. (1974). Mutamicins, biosynthetically created new sisomicin analogues. Journal of Antibiotics 27, 917-21.

Vastola, A. P., Altschaefl, J. \& Harford, S. (1980). 5-epi-sisomicin and 5-epi-gentamicin B substrates for aminoglycoside-modifying enzymes that retain activity against aminoglycoside-resistant bacteria. Antimicrobial Agents and Chemotherapy 17, 798-802.

Waitz, J. A., Miller, G. H., Moss, Jr., E. \& Chin, P. J. S. (1978). Chemotherapeutic evaluation of 5-epi-sisomicin (Sch 22591), a new semisynthetic aminoglycoside. Antimicrobial Agents and Chemotherapy 13, 41-8.

Watanakunakorn, C. (1978). Comparative in vitro activity of 5-episisomicin and five other aminoglycosides. Journal of Antimicrobial Chemotherapy 4, 474-7.

(Manuscript accepted 8 September 1986) 